\title{
Expanded porphyrins. Synthetic materials with potential medical utility*
}

\author{
Jonathan L. Sessler ${ }^{1, \dagger}$ Nicolai A. Tvermoes ${ }^{1}$, Julian Davis ${ }^{1}$, \\ Pavel Anzenbacher Jr. ${ }^{1}$, Karolina Jursíková ${ }^{1}$, Wataru Sato ${ }^{1}$, \\ Daniel Seidel ${ }^{1}$, Vincent Lynch ${ }^{1}$, Chris B. Black ${ }^{1}$, Andrew Try ${ }^{1}$, \\ Bruno Andrioletti ${ }^{1}$, Greg Hemmi ${ }^{2}$, Tarak D. Mody ${ }^{2}$, \\ Darren J. Magda ${ }^{2}$ and Vladimír Král ${ }^{3}$ \\ ${ }^{1}$ Department of Chemistry \& Biochemistry and the Institute for Cellular and Molecular \\ Biology, The University of Texas at Austin, Austin, TX 78712, \\ ${ }^{2}$ Pharmacyclics Inc., 995 East Arques Avenue, Sunnyvale, CA 94086-4593, USA, \\ ${ }^{3}$ Department of Analytical Chemistry, Institute of Chemical Technology, 16628 Prague 6, \\ Technická 5, Czech Republic
}

\begin{abstract}
A number of aromatic and nonaromatic expanded porphyrins have been prepared in the authors' laboratories. These are allowing a number of important themes to be explored, including the construction of novel cation- and anion-complexing agents and the generation of drug candidates with considerable therapeutic potential. In this paper, the use of gadolinium(III) and lutetium(III) texaphyrin derivatives as, respectively, adjuvants for X-ray radiation cancer therapy and photosensitizers for use in photodynamic treatments of cancer, atheromatous plaque, and age-related macular degeneration will be reviewed. Also discussed are the use of water soluble sapphyrins as potential fluorescent phosphate sensors and organic soluble 2,3dipyrrylquinoxaline derivatives as possible fluoride anion signaling agents. Recent synthetic work, designed to produce expanded porphyrins with new shapes and novel topologies, is also summarized.
\end{abstract}

\section{INTRODUCTION}

Expanded porphyrins [1-3], as the name implies, are polypyrrolic macrocycles that are bigger than porphyrins. Compared to their tetrapyrrolic 'cousins', expanded porphyrins generally contain a larger number of meso-like bridging atoms, a greater number of pyrrolic subunits, or both. The definition of expanded porphyrin also includes various heteroatom-derived systems (e.g., large polypyrrolic macrocycles containing non-carbon bridging atoms or analogues containing furan and thiophene subunits) as well as systems that, for one reason or another, are not formally aromatic.

Not surprisingly, given the generality of these definitions, a wide range of expanded porphyrins can easily be conceived. Nonetheless, the chemistry of such systems, often highly intriguing functional dyes, remains very much in its infancy. Still, enough work has been done to make it clear that expanded porphyrins have an important role to play in areas as diverse as X-ray cancer therapy, photodynamic therapy, and anion recognition. In this review, some of these potential applications are highlighted using examples from our own laboratories. Also presented are new synthetic advances that are leading to the production of hitherto unknown systems with interesting sizes, properties, and multi-dimensional topologies.

\footnotetext{
* Lecture presented at the 4th International Symposium on Functional Dyes-Science and Technology of Functional $\pi$-Electron Systems, Osaka, Japan, 31 May-4 June 1999, pp. 2009-2160.

$\dagger$ Corresponding author: E-mail: sessler@mail.utexas.edu
} 


\section{LANTHANIDE TEXAPHYRINS}

\section{General considerations}

One of the most seemingly obvious features of expanded porphyrins is that, being 'big', they should act to stabilize complexes containing cations that are larger than those normally bound in a 1:1 in-plane fashion by porphyrins (e.g. Zn(II), Co(II), Fe(II), etc.). This intuitively appealing idea continues to animate researchers world-wide and, indeed, it along with a desire to probe fundamental issues of aromaticity, stimulated much of the early activity in the area [4-6]. These efforts notwithstanding, however, few expanded porphyrins are known that actually work in this regard [6-10]. In fact, some 11 years after they were first introduced [11], the texaphyrins (e.g. 1-3), although difficult to isolate in their free-base forms, remain the only well-characterized expanded porphyrin systems for which an extensive 'large cation' coordination chemistry exists [10-12]. In contrast to the porphyrins and other polypyrrolic macrocycles reported in the literature, these aromatic, monoanionic ligands are known to form stable, nonlabile 1:1 complexes with a range of cations including those of the trivalent lanthanide series. This complexation ability, in conjunction with several other important attributes, including an unusual ease of reduction $\left(\mathrm{E}_{1 / 2} \approx 0.08 \mathrm{~V}\right.$ vs. NHE for $\mathbf{2}$ in aqueous media at $\mathrm{pH}$ 7) [13,14], a red-shifted lowest energy absorption maximum ( $\lambda_{\max }=732 \mathrm{~nm}$ for 3 ) [15,16], and an ability to localize in neoplastic tissues and atheromatous plaque, has made several of these systems, notably complexes $\mathbf{2}$ and $\mathbf{3}$, attractive candidates for use in a range of medically important applications. These latter include such diverse and potentially beneficial areas as X-ray radiation cancer therapy (XRT), photodynamic therapy for oncology (PDT), photoangioplasty (PA), and the light-based treatment of age-related macular degeneration (ARMD).

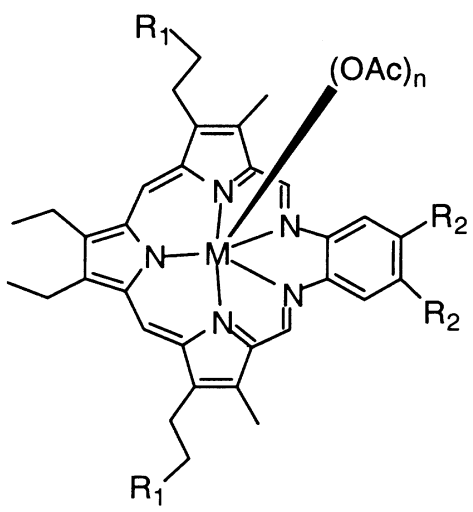

$$
\begin{aligned}
& \text { 1. } \mathrm{M}=\mathrm{H} ; \mathrm{n}=0 ; \mathrm{R}_{1}=\mathrm{R}_{2}=\mathrm{H} \\
& \text { 2. } \mathrm{M}=\mathrm{Gd}(\mathrm{III}) ; \mathrm{n}=2 ; \mathrm{R}_{1}=\mathrm{CH}_{2} \mathrm{OH} ; \\
& \quad \mathrm{R}_{2}=\mathrm{O}\left(\mathrm{CH}_{2} \mathrm{CH}_{2} \mathrm{O}\right)_{3} \mathrm{CH}_{3} \\
& \text { 3. } \mathrm{M}=\mathrm{Lu}(\mathrm{III}) ; \mathrm{n}=2 ; \mathrm{R}_{1}=\mathrm{CH}_{2} \mathrm{OH} ; \\
& \quad \mathrm{R}_{2}=\mathrm{O}\left(\mathrm{CH}_{2} \mathrm{CH}_{2} \mathrm{O}\right)_{3} \mathrm{CH}_{3}
\end{aligned}
$$

\section{Gd(II) texaphyrins. New adjuvants for radiation therapy}

Improving the clinical benefit of radiation therapy has been a long-standing goal in cancer research. One approach has been to administer agents to enhance the sensitivity of tumors to radiation therapy [17]. Currently, there is no FDA approved radiation sensitizer. Nonetheless, the need for an agent, or agents, that could help potentiate the efficacy of X-ray radiation therapy is cogent and real. Every year, more than 750000 patients in the United States undergo radiation treatment for cancer. Unfortunately, in many patients the treatment is of limited value because of inadequate efficacy or serious toxicity. It is believed that this often-times limiting therapeutic benefit both reflects damage to normal cells and derives from the presence of hypoxic cells within the tumor. Hypoxic cells are typically 2.5-3 times less sensitive to radiation than oxygenated cells. Not surprisingly, therefore, several different approaches to overcoming the radioresistance of hypoxic cells, e.g. radiation fractionation, administration of hyperbaric oxygen, etc., have been pursued. While varying degrees of success has been encountered using some of these strategies, an alternative approach, involving the use of radiation sensitizers, is also attractive [17]. In this context, the water soluble gadolinium(III) texaphyrin derivative 2 (XCYTRIN ${ }^{\mathrm{TM}}$ ) may have a special role to play. This agent abets the production of reactive oxygen species in the presence of ionizing radiation and may operate via mechanisms that are very different from those of other more classic electron affinic radiation sensitizers [18]. Further, it contains a highly paramagnetic cation, Gd(III), coordinated in its central core. This means that XCYTRIN ${ }^{\mathrm{TM}}$, and the cancerous lesions to which it localizes, may be visualized readily using magnetic resonance imaging (MRI) methods [13,19]. 
To date the efficacy of XCYTRIN ${ }^{\mathrm{TM}}$ injection, an agent being developed by Pharmacyclics Inc. of Sunnyvale, California, has been demonstrated in vivo in several murine tumor models (e.g. EMT6, SMT-F, etc.) that have very different biological behavior $[13,18]$ and in a Phase Ib/II clinical trial of patients with brain metastases [20].

In the animal studies, both drug dependent responses as well as substantial tumor growth delays and cures were seen to result from the use of drug doses and radiation fractionation schedules similar to those that might be used clinically $[13,18]$.

In the Phase Ib/II clinical trial, involving a 61 patient study base, improved survival was demonstrated for patients receiving XCYTRIN ${ }^{\mathrm{TM}}$ compared to two independent case-matched historical controls [20]. Patients receiving XCYTRIN ${ }^{\mathrm{TM}}$ were less likely to die of complications related to tumor progression in the brain indicating that the drug improved local control by radiation therapy (Fig. 1). MRI scanning, carried out in the context of these studies and during a prior Phase I trial, confirmed that XCYTRIN ${ }^{\mathrm{TM}}$ accumulates, and is retained selectively, in tumors and does not localize appreciably in adjacent normal tissue $[19,20]$. These salubrious findings are engendering considerable enthusiasm for this experimental drug and have helped provide, inter alia, the rationale for testing XCYTRIN ${ }^{\mathrm{TM}}$ expeditiously in the context of an ongoing randomized Phase III clinical trial. They are also supporting the recent decision on the part of the NCI to sponsor Phase I clinical studies of XCYTRIN ${ }^{\mathrm{TM}}$ as a radiation enhancer for several other indications (e.g., lung, pancreas, head and neck etc.)
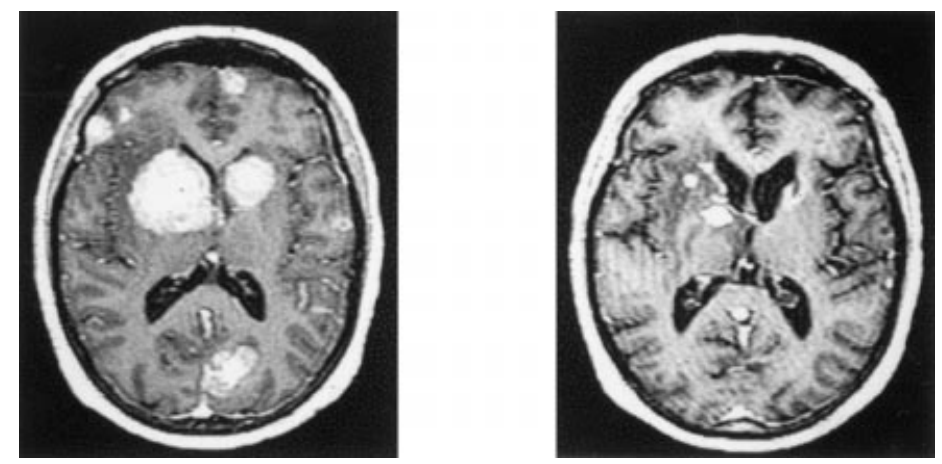

Fig. 1 (Left) MRI scan of the head showing multiple brain metastases in a severely ill patient with breast cancer entered in Pharmacyclics Inc.'s Phase Ib/II clinical trial of XCYTRIN ${ }^{\mathrm{TM}}$ injection, an experimental radiation enhancing drug. (Right) Eleven months after receiving radiation therapy and XCYTRIN ${ }^{\mathrm{TM}}$ injection, the patient remains in remission with minimal signs of residual disease. Copyright 1998 Pharmacyclics Inc.; reproduced with permission.

\section{Lu(III) texaphyrins. Novel photosensitizers with diverse applications}

Photodynamic therapy (PDT) for cancer is an emerging modality that is predicated on the use of a biocompatible dye that, after injection into a patient, is retained selectively in a tumor site [1-3]. Irradiation of the dye with visible light then serves to produce singlet oxygen and other reactive oxygen species that act as the actual cancer-killing cytotoxins. The binary nature of this therapy, wherein both the sensitizing dye (photosensitizer) and irradiating light may be used to target the tumor selectively, makes photodynamic therapy a particularly attractive approach to treating neoplastic disease. Unfortunately, only one photosensitizer, PHOTOFRIN ${ }^{\circledR}$ (porfimer sodium), has so far been approved by the FDA [3]. Further, problems inherent to this drug product, including (i) poor light absorption in the 700-800 nm spectral region where bodily tissues are most transparent and (ii) low clearance rates and sustained levels of induced cutaneous phototoxicity, have limited the adoption of PDT as a cancer treating modality. On the other hand, the lutetium(III) texaphyrin derivative 3 (Lu-Tex) is endowed with a number of attributes that make it seemingly ideal as a photosensitizer, not only for PDT but also related applications such as PA and the light-based treatment of ARMD. It absorbs light in the far-red spectral region $\left(\lambda_{\max }=732 \mathrm{~nm}\right.$ ), localizes well to tumors (selectivity factors of $>10: 1$ relative to surrounding tissue are routinely observed), generates singlet oxygen in high quantum yield (between 10 and $70 \%$ depending 
on conditions) [3,15], and may be formulated in the form of sterile, injectable aqueous solutions $[16,18,21]$.

LUTRIN $^{\mathrm{TM}}$ photosensitizer, a Lu-Tex drug product, is being developed by Pharmacyclics Inc. for use in the PDT of cancer. It demonstrates remarkable PDT activity in animal tumor models $[16,18,22]$ and was found to be efficacious in a Phase I clinical study involving photodynamic treatments of metastatic tumors involving the skin and subcutaneous tissues [21]. Currently, LUTRIN ${ }^{\mathrm{TM}}$ injection is in Phase II clinical trials for recurrent breast cancer to the chest wall.

ANTRIN $^{\mathrm{TM}}$ photosensitizer is the trade name of the formulation of Lu-Tex that is being developed by Pharmacyclics Inc. for use in photoangioplasty. Photoangioplasty is a potentially all-important new treatment for atheromatous disease that resembles more classic photodynamic cancer therapy in terms of underlying photophysics if not in specific details. The basic idea involves administering a photosensitizing drug that localizes to atherosclerotic plaque and then using light-based activation (through e.g., a fiber optic catheter inserted into the blood vessel) to effect plaque removal. Given that this is a procedure that needs to be effected in the presence of blood, the advantages of using ANTRIN ${ }^{\mathrm{TM}}$ become clear; this experimental drug not only localizes to plaque but is also activated at a wavelength $(732 \mathrm{~nm})$ where blood is maximally transparent.

To date, the efficacy of ANTRIN ${ }^{\mathrm{TM}}$ has been demonstrated in various animal models $[18,23]$. This same agent has also been tested in a now-completed Phase I clinical trial targeting the treatment of peripheral arterial disease. While data analysis is still ongoing, promising results appear to have been obtained in this trial. Specifically, Razavi et al. have reported that 12 of 14 evaluable patients treated with ANTRIN $^{\mathrm{TM}}$ photoangioplasty for symptomatic peripheral arterial disease involving the femoral arteries demonstrated an increase in minimal luminal diameter assessed one month following the procedure (cf., e.g. Fig. 2) [24]. To the extent the results prove generalizable, it would mark the first time a nonmechanical clinical technique is successful in reducing arteriosclerosis.
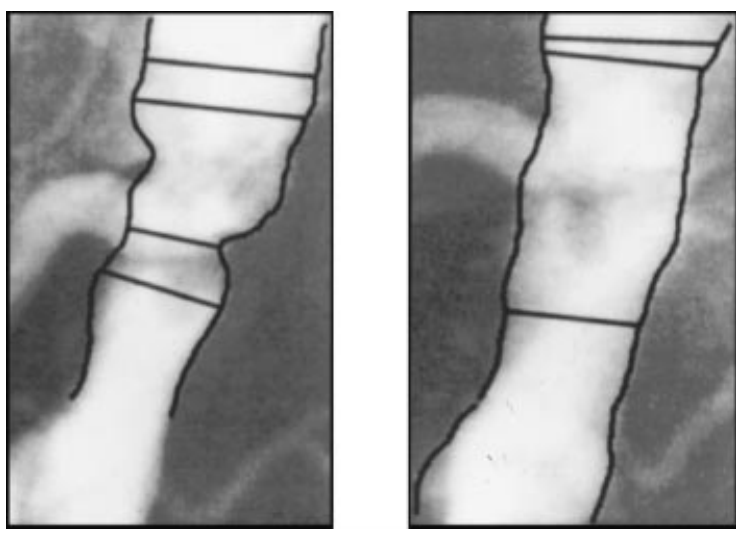

Fig. 2 Left. Pretreatment angiogram of the femoral artery of a patient enrolled in Pharmacyclics Inc.'s Phase I study of ANTRIN ${ }^{\mathrm{TM}}$ photosensitizer showing the severe narrowing of this vessel caused by atherosclerosis. Right: One month after a single treatment with ANTRIN ${ }^{\mathrm{TM}}$ photosensitizer-based angioplasty, a repeat angiogram shows a 50\% increase in the diameter of the arterial opening and increased blood flow. Copyright 1998 Pharmacyclics Inc.; reproduced with permission.

Many of the same attributes that makes Lu-Tex so attractive in terms of treating cancer and arteriosclerosis, also make it of interest in terms of treating ARMD. This condition, which is the leading cause of severe visual impairment and blindness in Americans over age 60, is caused by angiogenesis of abnormal vessels in the choroid of the retina. These diseased vessels leak fluid, which results in visual impairment. While currently there is no cure for ARMD, photosensitizing drugs that localize in this neovasculature in conjunction with site-specific far red-light activation offer the possibility for clinically useful control and, in fact, a number of such agents are in development for this purpose. OPTRIN ${ }^{\mathrm{TM}}$, a drug product derived from Lu-Tex (3) has been shown (when activated with red light) to destroy diseased vessels in preclinical studies and is currently being evaluated for safety, drug/light dosing, and efficacy in 
a Phase Ib/II clinical trial being conducted by Alcon Laboratories Inc. Meanwhile, a different photosensitizing agent, VISUDYNE ${ }^{\mathrm{TM}}$, being developed by QLT and Ciba Vision, has completed a Phase III randomized trial involving the 'wet' form of ARMD. Thus, it appears likely that the scope of photodynamic therapy will soon be extended so as to include this particularly important ocular realm.

\section{SAPPHYRINS, ANION BINDING, AGENTS PAR EXCELLENCE}

\section{Background}

While the texaphyrins may be the first expanded porphyrins to display a well-defined coordination chemistry, it was the sapphyrins (e.g., 4-9) that were actually the first to be recorded in the literature. This class of blue-green (i.e., sapphire-like) materials was first discovered accidentally by R. B. Woodward and his co-workers during the course of early work devoted to the synthesis of vitamin $\mathrm{B}_{12}$ [4]; they were then independently synthesized by members of his team and by A. W. Johnson and co-workers [5]. Unfortunately, the tedious nature of these syntheses and the resulting restricted product availability precluded extensive studies of this intriguing system (although some unsuccessful attempts to obtain uranyl complexes were noted by Woodward and his coworkers [4]).

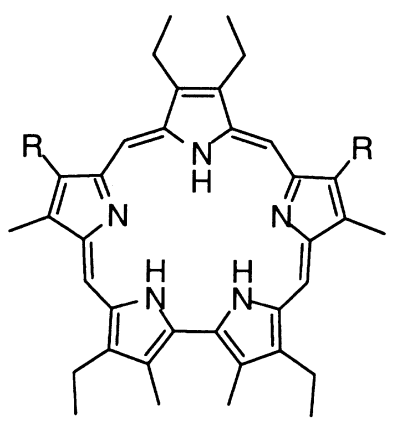

$$
\mathrm{A}=\xi \widetilde{\mathrm{CO}_{2} \mathrm{CH}_{3}}
$$<smiles>C=CCCC(=O)NCCO</smiles>
4. $R=E t$
7. $R=C$
5. $R=A$
8. $R=D$
6. $R=B$
9. $R=E$<smiles>C=PCCCC(=O)NCC(O)C(O)C(O)CO</smiles>

With the advent of an improved synthesis of sapphyrin in 1990 [25], however, it suddenly became possible to obtain usable quantities of these fascinating pentapyrrolic heteroannulenes. Efforts, therefore, quickly turned to the problem of structural characterization. Here, it was immediately found that efforts to crystallize the bis- $\mathrm{HPF}_{6}$ salt of sapphyrin 4 gave rise instead to a mixed $\mathrm{HF}-\mathrm{HPF}_{6}$ salt wherein the fluoride anion was found to be centrally encapsulated within the core (and plane) of the diprotonated pentaaza macrocycle via five, near-symmetric hydrogen bonds [25]. This result, which was without precedent in the chemistry of porphyrins, led to the suggestion that sapphyrin and other expanded porphyrins might function as unique and highly effective anion binding receptors [1,25-27].

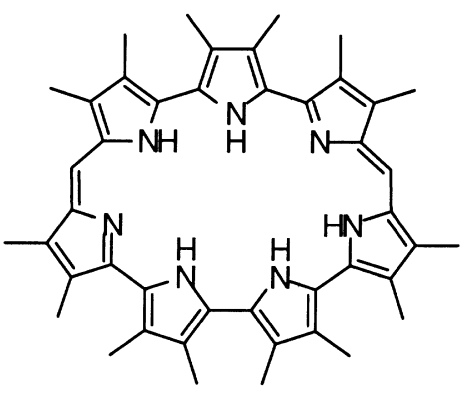

10

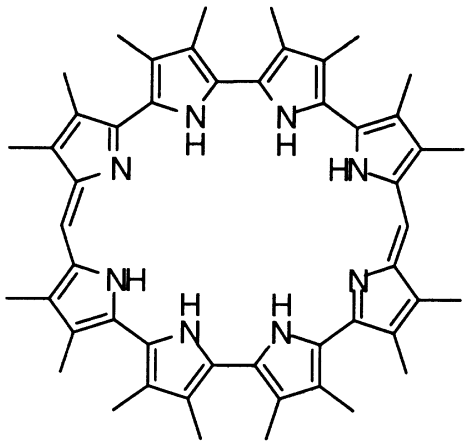

11 
To date, considerable support for this proposal has been obtained. For instance, systems as diverse as rubyrin [28], rosarin [29], amethyrin [30], and turcasarin [31] have been shown, when protonated, to bind anions in the solid state. The protonated forms of other more newly prepared systems, including the previously unknown heptaphyrin and octaphyrin derivatives $\mathbf{1 0}$ and 11, constructed via a noval oxidative ring closure procedure, also appear to bind appropriately sized anionic substrates within their central cores. In the particular case of sapphyrin, detailed analyses, including U-tube transport studies and silica gel-based HPLC separation experiments, revealed that a range of phosphorylated anions, including mononucleotides and DNA, are bound with high specificity (relative to other biological anions) both in solution and in the solid state [26,27,32-35]. These findings, in turn, led us to consider that sapphyrins might be useful as phosphate anion sensors.

\section{Sapphyrins as potential in vitro fluorescence-based phosphate anion sensors}

Phosphorylated entities play essential roles in biology and medicine. They take center stage in areas as disparate as osmotic pressure regulation, cell signaling, energy transduction, and genetic information control [36]. Even the simplest of all phosphate anions, inorganic phosphate $\left(\mathrm{P}_{\mathrm{i}}\right)$ plays a critical role in, among other things, regulating metabolism and defining cell status. In spite of its importance, however, no good cell-compatible fluorescent sensor for $\mathrm{P}_{\mathrm{i}}$ currently exists. However, as discussed briefly below, water soluble sapphyrins, such as 7-9, appear quite promising in this regard.

The reason water soluble sapphyrins appear promising as potential in vitro phosphate anion sensors is that they are generally highly aggregated and non-fluorescent at neutral $\mathrm{pH}$. However, as indicated in Fig. 3, even at this $\mathrm{pH}$ (conditions under which sapphyrin is monoprotonated), addition of buffered sodium phosphate (but not sodium chloride) services to enhance substantially the fluorescence of sapphyrin. The fact that water soluble sapphyrins (e.g. 7) are relatively non-cytotoxic and localize well to tumors in murine models (cf. Fig. 4) supports our contention that these systems may be useful as biological $\mathrm{P}_{\mathrm{i}}$ sensors.

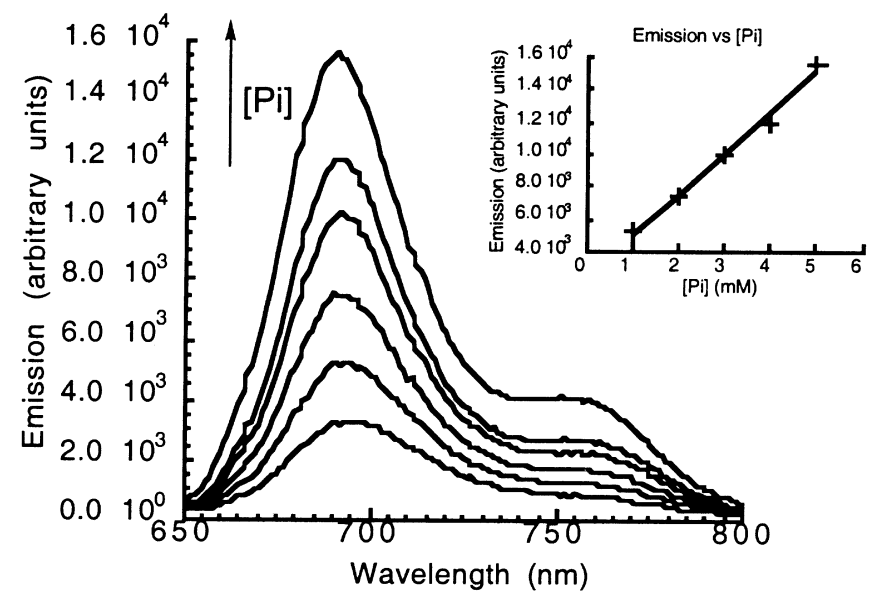

Fig. 3 Increase in fluorescence intensity seen when sapphyrin $9(2 \mu \mathrm{M})$ is titrated with increasing quantities of $P_{i}$ in water at pH $7.0\left(\lambda_{\text {excit. }}=450 \mathrm{~nm}\right)$. The inset shows a plot of the emission intensity vs. $\left[\mathrm{P}_{\mathrm{i}}\right]$.

\section{2,3-DIPYRRYLQUINOXALINES. SIMPLE-TO-MAKE ANION SENSORS}

While the potential advantages of sapphyrin as a potential anion sensor are clear, one of the disadvantages associated with this and most other expanded porphyrin systems is that they are hard to make. Accordingly, considerable effort in our laboratories is being devoted to the preparation of polypyrrolebased anion binding systems that are easier to make. One approach that appears attractive involves the use of modified calixpyrroles bearing fluorescent reporter groups (e.g. 12) [37]. Another, is to generate pyrrolic entities containing built-in chromophores. In accord with this latter reasoning, we decided to explore the use of 2,3-dipyrrylquinoxalines (e.g. 13-16) as potential anion receptors and sensors.

Although the parent system (13) has been known in the literature since 1911 [38], the application of 


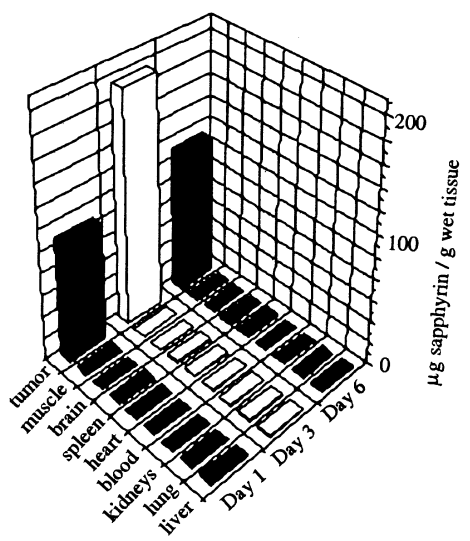

Fig. 4 Time course and biolocalization of sapphyrin 7 in a xenographic pancreatic cancer mouse model. The concentration of sapphyrin at the indicated sites was determined by extraction and authentication following sacrifice.

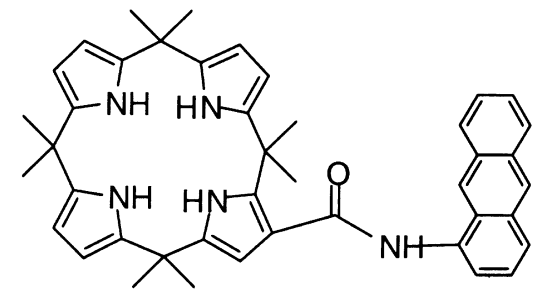

12

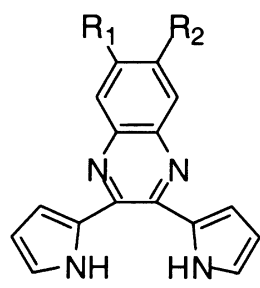

13. $R_{1}=R_{2}=H$

14. $R_{1}=R_{2}=O M e$

15. $R_{1}=R_{2}=N_{2}$

16. $R_{1}=H, R_{2}=\mathrm{NO}_{2}$<smiles></smiles>

17<smiles>CC(C)(c1ccc[nH]1)c1ccc(-c2nc3ccccc3nc2-c2ccc(-c3nc4ccccc4nc3-c3ccc[nH]3)[nH]2)[nH]1</smiles>

18

2,3-dipyrrylquinoxalines to the problem of anion recognition has not, to the best of our knowledge, been previously considered. On the other hand, the ease of synthesis (involving reaction of pyrrole with oxalyl chloride followed by condensation of the resulting diketone with $o$-phenylenediamine), the myriad possibilities for derivatization (to produce, e.g. 14-16), and the presence of both $\mathrm{NH}$ donor functionality and a built-in quinoxaline chromophore, led us to consider that such systems would be worth exploring. As can be inferred from Fig. 5, this approach does indeed work well. For instance, the mononitro derivative 16, when dissolved in dichloromethane, is pale orange in the absence of an anion and remains so in the presence of chloride anion. However, addition of fluoride anion (in the form of its 


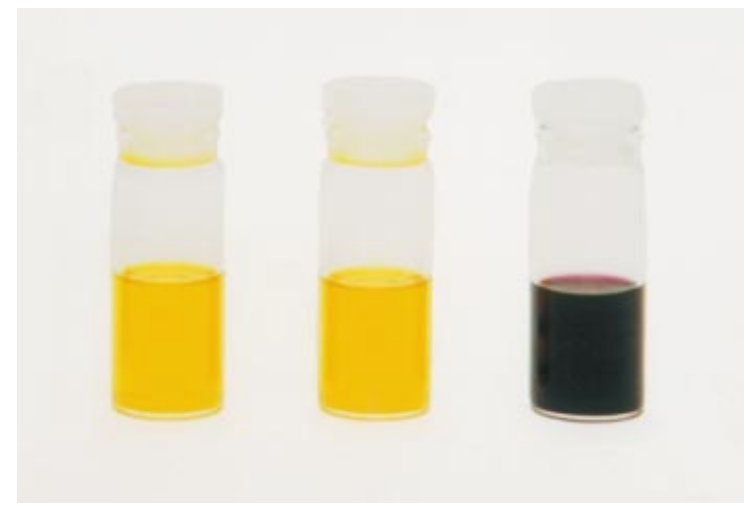

Fig. 5 Dichloromethane solutions of 6-nitro-2,3-dipyrrylquinoxaline (16) as they appear, from left to right, in the absence of added anion, in the presence of excess tetrabutylammonium chloride, and in the presence of excess tetrabutylammonium fluoride.

tetrabutylammonium salt) causes the solution to undergo a dramatic, naked-eye detectable change from orange to purple, leading us to suggest that system $\mathbf{1 6}$, and its analogues, could provide a possible solution to the still-unsolved problem of colorimetric fluoride anion sensing. A further, particularly gratifying aspect of this chemistry is that extensions to higher order systems appear possible. Indeed, in work that is still very much in progress, we have succeeded in isolating the 'expanded calixpyrrole'-like hexamer $\mathbf{1 7}$, as well as a range of open chain products (e.g. 18) whose anion binding characteristics are currently being explored.

\section{TOWARDS THE FUTURE. THE GENERATION OF 3-DIMENSIONAL SYSTEMS}

The considerable body of work that has now been devoted to the construction and study of expanded porphyrins has served to establish unequivocally that this class of matrocyclic materials occupies an important niche within the biosphere of functional dyes. Still, a number of challenges remain, including a need for improved synthetic methodologies and further biological study of those systems that show particularly desirable attributes. On a very different level, one of the great outstanding challenges, in our opinion, is to construct systems with well-defined three-dimensional topologies. Such putative products, bearing structural analogy to other well-known three dimensional supramolecular systems, such as cryptands, catenanes, and rotaxanes, could serve to expand the scope of the field considerably while, at the same time, acting as quite selective polytopic receptors.

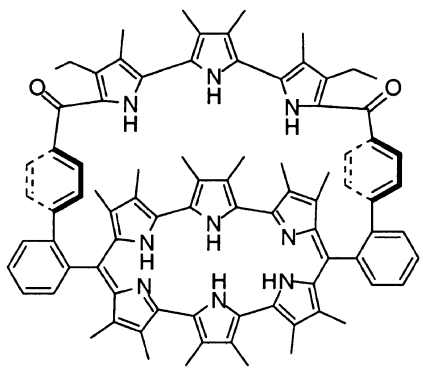

19

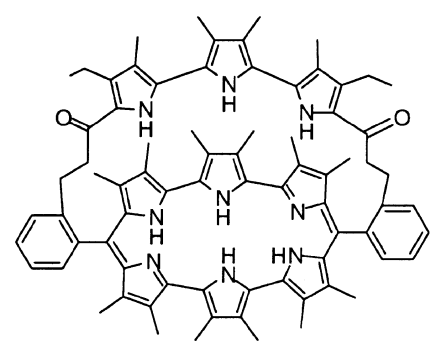

20

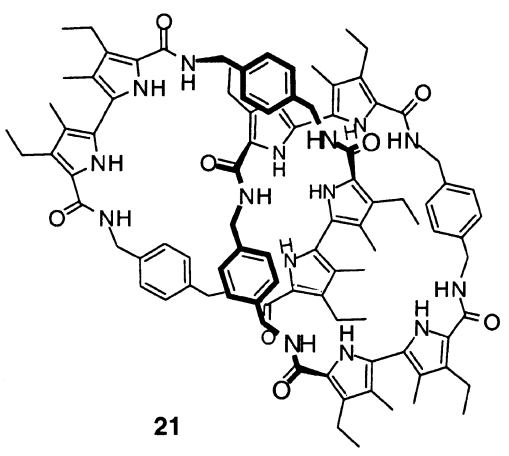

The first hint, at least for us, that expanded porphyrins need not be planar came with the synthesis and structural characterization of turcasarin [31]. This system was found to adopt a figure-eight conformation both in solution and in the solid state, as do several other recently-prepared expanded porphyrin systems [1]. This led us to propose that covalently linked system, wherein topological three-dimensionality was enforced, would be of interest. Towards this end, we prepared and reported some time ago, a tripyrranestrapped porphyrin [39]. More recently, in work that is still ongoing, we succeeded in preparing topologically related, but chemically more robust, terpyrrole-strapped amethyrin derivatives, specifically 
'cryptophyrins' 19 and 20. In collaboration with Prof. Vögtle, we were also able to synthesize and characterize a first-ever polypyrrole-containing catenane (system 21), a compound that acts as a remarkably effective anion binding agent [40]. With these examples in hand, and many others readily conceivable, it is our opinion that the future of expanded porphyrin research is bright. Much has been accomplished but much, much more remains to be done.

\section{ACKNOWLEDGEMENTS}

This work was supported in part by the National Institutes of Health (grants CA 68682, GM58907 and TW 00682 to J.L.S.), the National Science Foundation (CHE-9725399 to J.L.S.), Pharmacyclics Inc. (to J.L.S.), the Texas ARP, the Howard Hughes Foundation (V.K. and J.L.S.), and the Grant Agency and Ministry of Education of the Czech Republic (grants 203/96/0740, 203/97/1099 and VF 97135 to V.K.)

\section{REFERENCES}

1 J. L. Sessler, S. J. Weghorn. Expanded Contracted \& Isomeric Porphyrins, Elsevier, Oxford (1997).

2 A. Jasat, D. Dolphin. Chem. Rev. 97, 2267-2340 (1997).

3 T. D. Mody, J. L. Sessler. In Supramolecular Technology (D. Reinhoudt, ed.). pp. 245-299. Wiley \& Sons, Chichester (1999), and references therein.

4 V. J. Bauer, D. L. J. Clive, D. Dolphin, J. B. Paine III, F. L. Harris, M. M. King, J. Loder, S.-W.C. Wang, R. B. Woodward. J. Am. Chem. Soc. 105, 6429-6436 (1983).

5 M. J. Broadhurst, R. Grigg, A. W. Johnson. J. Chem. Soc., Perkin I 2111-2116 (1972).

6 V. W. Day, T. J. Marks, W. A. Wachter. J. Am. Chem. Soc. 97, 4519-4527 (1975).

7 A. K. Burrell, G. Hemmi, V. Lynch, J. L. Sessler. J. Am. Chem. Soc. 113, 4690-4692 (1991).

8 J. L. Sessler, T. D. Mody, V. Lynch. Inorg. Chem. 31, 529-531 (1992).

9 J. L. Sessler, A. Gebauer, M. C. Hoehner, V. Lynch. Chem. Commun. 1835-1836 (1998).

10 J. L. Sessler, G. Hemmi, T. D. Mody, T. Murai, A. Burrell, S. W. Young. Acc. Chem. Res. 27, 43-50 (1994).

11 J. L. Sessler, T. Murai, V. Lynch, M. Cyr. J. Am. Chem. Soc. 110, 5586-5588 (1988).

12 J. L. Sessler, T. D. Mody, G. W. Hemmi, V. Lynch. Inorg. Chem. 32, 3175-3187 (1993).

13 S. W. Young, Q. Fan, A. Harriman, J. L. Sessler, W. C. Dow, T. D. Mody, G. Hemmi, Y. Hao, R. A. Miller. Proc. Natl. Acad. Sci. 93, 6610-6615 (1996).

14 J. L. Sessler, N. A. Tvermoes, D. M. Guldi, T. D. Mody, W. E. Allen. J. Phys. Chem. A 103, 787-794 (1999).

15 J. L. Sessler, W. C. Dow, D. O’Connor, A. Harriman, G. Hemmi, T. D. Mody, R. A. Miller, F. Qing, S. Springs, K. Woodburn, S. W. Young. J. Alloys Compounds 249, 146-152 (1997).

16 S. W. Young, K. W. Woodburn, M. Wright, T. D. Mody, Q. Fan, J. L. Sessler, W. C. Dow, R. A. Miller. Photochem. Photobiol. 63, 892-897 (1996).

17 T. H. Wasserman, J. D. Chapman, C. N. Coleman, M. M. Kligerman. In Principles and Practice of Radiation Oncology (C. A. Peres, L. W. Brady, eds), pp. 685-704. Lippincott-Raven, Philadelphia (1998).

18 J. L. Sessler, R. A. Miller. Biochem. Pharmacol., in press.

19 D. I. Rosenthal, P. Nurenberg, C. R. Becerra, E. P. Frenkel, D. P. Carbonne, B. L. Lum, R. Miller, J. Engel, S. You, D. Miles, M. F. Renschler. Clin. Cancer Res. 5, 739-745 (1999).

20 B. Timmerman, P. Carde, C. Koprowski, D. Arwood, J. Ford, M. Mehta, R. Tishler, J. Larner, R. Miller, S. Koffler-Horovita, D. Hoth, M. Renschler. Int. J. Radiat. Oncol. Biol. Phys. 42, 198 (1998).

21 M. F. Renschler, A. R. Yuen, T. J. Panella, T. J. Wieman, S. Dougherty, L. Esserman, M. Panjehpour, S. W. Taber, V. H. Fingar, E. Lowe, J. S. Engel, B. Lum, K. W. Woodburn, W.-F. Cheong, R. A. Miller. Proc. SPIE Int.Opt. Eng. 3247, 35-39 (1998).

22 K. W. Woodburn, Q. Fan, D. Kessel, Y. Luo, S. W. Young. J. Invest. Dermatol. 110, 746-751 (1998).

23 J. D. Arbour, E. J. Connolly, K. Graham, D. Carson, N. Michaud, T. Flotte, E. S. Gragoudas, J. W. Miller. Invest. Ophthal. Vis. Sci. 40, 2111 (1999).

24 M. K. Razavi, S. Rockson, A. Szuba, S. Yousef, J. Cooke, D. Adelman, S. Filardo. Radiology 210, GH20 (1999).

25 J. L. Sessler, M. J. Cyr, V. Lynch, E. McGhee, J. Ibers. J. Am. Chem. Soc. 112, 2810-2813 (1990). 
26 J. L. Sessler, A. Andrievsky, J. W. Genge. In Advances in Supramolecular Chemistry (G. W. Gokel, ed.), Vol. 4, pp. 97-142. JAI Press Inc., Greenwich, Connecticut (1997).

27 J. L. Sessler, P. I. Sansom, A. Andrievsky, V. Král. In Supramolecular Chemistry of Anions (A. Bianchi, K. Bowman-James, E. Garcia-Espana, eds), pp. 355-419. VCH Verlag, Weinheim, (1997).

28 J. L. Sessler, T. Morishima, V. Lynch. Angew. Chem. Intl. Ed. Engl. 30, 977-980 (1991).

29 J. L. Sessler, S. J. Weghorn, T. Morishima, M. Rosingana, V. Lynch, V. Lee. J. Am. Chem. Soc. 114, 8306-8307 (1992).

30 J. L. Sessler, S. J. Weghorn, Y. Hisaeda, V. Lynch. Chem. Eur. J. 1, 56-67 (1995).

31 J. L. Sessler, S. Weghorn, V. Lynch, M. R. Johnson. Angew. Chem. Int. Ed. Engl. 33, 1509-1512 (1994).

32 V. Král, J. L. Sessler, H. Furuta. J. Am. Chem. Soc. 114, 8704-8705 (1992).

33 B. L. Iverson, R. E. Thomas, V. Král, J. L. Sessler. J. Am. Chem. Soc. 116, 2663-2664 (1994).

34 V. Král, H. Furuta, K. Shreder, V. Lynch, J. L. Sessler. J. Am. Chem. Soc. 118, 1595-1607 (1996).

35 B. L. Iverson, K. Shreder, V. Král, P. Sansom, V. Lynch, J. L. Sessler. J. Am. Chem. Soc. 118, 1608-1616 (1996).

36 L. Stryer. Biochemistry, 4th Ed., pp. 444-507 W. H. Freeman \& Co., New York (1995).

37 J. L. Sessler, P. Anzenbacher Jr., K. Jursíková, H. Miyaji, J. W. Genge, N. A. Tvermoes, W. E. Allen, J. Shriver, P. Gale, V. Král. Pure Appl. Chem. 70, 2401-2408 (1998).

38 B. Oddo. Gazz. Chim. Ital. 41, 248-255 (1911).

39 J. L. Sessler, R. M. Dávila, V. Král. Tetrahedron Lett. 37, 6469-6472 (1996).

40 A. Andrievsky, F. Ahuis, J. L. Sessler, F. Vögtle, D. Gudat, M. Moini. J. Am. Chem. Soc. 120, 9712-9713 (1998). 